\title{
The persisting gender gap in hypertension management and control in Germany: 1998 and 2008-2011
}

\author{
Giselle Sarganas $^{1,2}$ and Hannelore K Neuhauser ${ }^{1,2}$
}

Hypertension is a major risk factor for cardiovascular morbidity; therefore, its control is very important. International Guidelines recommend the same hypertension management in men and women; however, studies suggest that management of hypertension differs. This study explores gender-age disparities in the management and control of hypertension in Germany in 1998 and 2008-2011. Data from the German Health Examination Surveys (GNHIES98 1998, $n=7124$ and DEGS1 2008-2011, $n=7988$, age 18-79 years), including standardized blood pressure measurements and Anatomical Therapeutic Chemical medication codes, were analyzed by gender and two age groups. For 1998 and 2008-2011 in Germany, the gender gap in hypertension management persisted without significant changes. Hypertensive men in 2008-2011 had lower awareness of their condition (78.3 vs. $86.8 \%$ ), less treatment for hypertension $(65.3$ vs. $79.2 \%)$, less control of hypertension $(45.4$ vs. $57.5 \%)$ and less treatment among those aware of their condition ( 83.9 vs. $91.5 \%)$ than did women. These gender differences were greater in younger compared with older adults (18-54 years vs. 55-79 years). No gender differences were observed in control of hypertension among those treated in 1998; however, subsequent improvement was less in younger men compared with the other age-gender groups, leading to a new gender gap in 18-54-year olds (women $84.8 \%$, men $63.9 \%$ ). Younger women used more $\beta$-blockers and less angiotensin-converting enzyme inhibitors (ACEI) than younger men. Factors positively associated with control among those treated for hypertension in the younger group were being a woman, using $\beta$-blockers or using ACEI, or angiotensinreceptor blockers. In the older group, diabetes was negatively associated with control of hypertension, whereas having cardiovascular comorbidities was positively associated. Gender disparities in hypertension management and control still exist in Germany but may be masked because they are age-dependent. Hypertension Research (2016) 39, 457-466; doi:10.1038/hr.2016.5; published online 28 January 2016

Keywords: control; gender-gap; Germany; hypertension management; trends

\section{INTRODUCTION}

High blood pressure (BP) is one of the greatest worldwide public health concerns, and its control could significantly reduce cardiovascular morbidity and mortality in both men and women. ${ }^{1-4}$ Among the most important factors associated with the improvement of BP control is the use of antihypertensive medication, ${ }^{5,6}$ as well as having regular BP measurement, including self-measurement. ${ }^{7,8}$ European Guidelines for the management of arterial hypertension, ${ }^{9}$ which are pursued in Germany, recommend the following five main antihypertensive groups for the initiation and maintenance of antihypertensive treatment, either as monotherapy or in combination diuretics: $\beta$-blockers, calcium-channel blockers, angiotensin-converting enzyme inhibitors (ACEI) and angiotensin-receptor blockers (ARB). European Guidelines also state that there is no evidence that different choices made for hypertension treatment should be based on age or gender (except for caution in using the renin-angiotensin system blockers in women with child-bearing potential because of the possible teratogenic effects). ${ }^{9}$ Despite these gender-neutral recommendations, there are disparities in hypertension management and control. Over decades, surveys showed higher awareness, treatment and control rates for hypertension in women compared with men in several European countries, Canada and the United States. ${ }^{6,10-14}$ More recently, a narrowing of the hypertension management gender gap was reported for Canada ${ }^{15}$ and England, ${ }^{16}$ but not for Germany. ${ }^{12,17}$ Therefore, the purpose of this study is to further explore the gender-age disparities in the management and control of hypertension in Germany, including gender-specific analyses of antihypertensive medication use and BP measurement patterns.

\section{METHODS}

Study population

Nationwide data on BP in the population of Germany based on standardized measurements is available only from national health examination surveys; the

\footnotetext{
${ }^{1}$ Department of Epidemiology and Health Monitoring, Robert Koch Institute, Berlin, Germany and ${ }^{2}$ DZHK, German Center for Cardiovascular Research, Partner Site, Berlin, Germany

Correspondence: Dr G Sarganas, Department of Epidemiology and Health Monitoring, Robert Koch Institute, General Pape Str. 62-66, 12101 Berlin, Germany.

E-mail: sarganas-margolisg@rki.de

Received 8 October 2015; revised 11 December 2015; accepted 17 December 2015; published online 28 January 2016
} 
two most recent are the German National Health Interview and Examination Survey 1998 (GNHIES98) and the German Health and Examination Survey for Adults 2008-2011 (DEGS1). ${ }^{18,19}$ The surveys consisted of a nationwide two-stage clustered sample from local population registers of adults aged 18-79 years (7124 GNHIES98 participants from 120 communities and 7988 DEGS1 participants from 180 communities). All GNHIES98 participants were invited to re-participate in DEGS1 (response rate $64 \%, n=3795$ ). An additional crosssectional sample of 4193 first-time participants (response rate 42\%) was recruited for DEGS1 based on the same sampling design. Both GNHIES98 and DEGS1 include largely identical survey methods and measurement protocols (self-administered questionnaires, computer-assisted personal interviews conducted by a study physician, medical examinations, physiological measurements and blood and urine samples), making possible the estimation of time trends. ${ }^{19}$ Participants provided written informed consent before interview and examination in both studies.

\section{Measurements and definitions}

Three BP measurements were taken in both surveys for the right arm at 3-min intervals after a non-strenuous part of the examination and an additional 5-min rest. Participants sat on a height-adjustable chair, back supported, arm lying on a table at heart level, feet on the floor and legs uncrossed. A standard mercury sphygmomanometer (Erkameter 3000, Bad Tölz, Germany) was used in GNHIES98, and an automated oscillometric device (Datascope Accutorr Plus, Mahwah, NJ, USA) was used in DEGS1. Three different cuff sizes were used in each study. GNHIES98 BP data were calibrated for comparison with DEGS1 data based on a validation study to account for cuff and device differences. ${ }^{19,20}$ The second and third measurements were averaged.

Antihypertensive medication intake was recorded during the medical interview for 7099 adults in GNHIES98 and for 7091 adults in DEGS1. Participants were requested to bring all original medication packages they had used in the previous 7 days and all Anatomical Therapeutic Chemical (ATC) codes were documented. $^{21}$

Hypertension was defined as the mean systolic BP $(\mathrm{SBP}) \geqslant 140 \mathrm{~mm} \mathrm{Hg}$, or mean diastolic BP (DBP) $\geqslant 90 \mathrm{~mm} \mathrm{Hg}$, or the use of antihypertensives (ATC-codes $\mathrm{C} 02$ antihypertensives, C03 diuretics, C07 $\beta$-blockers, C08 calcium-channel blockers or C09 ACEI and ARB). However, as the indication for taking these drugs may be other than hypertension, antihypertensive medication was only used for defining prevalent and treated hypertension if the participants reported having hypertension. Awareness was defined as hypertension in individuals who had been told by a physician that they had elevated BP or hypertension.

For the analysis of hypertension treatment and control, six classes of antihypertensives were examined. On the basis of the detailed ATC-codes (Supplementary Information), they were diuretics (including all diuretics and thiazide-diuretics), $\beta$-blockers, calcium-channel blockers, ACEI, ARB and other antihypertensives). Monotherapy was defined as the use of only 1 antihypertensive agent, and polytherapy (combination therapy) was defined as the use of $>1$ antihypertensive agent. Single-pill antihypertensive-combination users were considered to be receiving polytherapy. If a person used antihypertensive medication containing $>1$ active ingredient, the person was counted once within each of the antihypertensive classes.

In contrast to previous analyses, ${ }^{12} 10$ participants with imprecise selfreported medication (as compared with those who brought medication packages) were not counted as treated in drug-class-specific analyses. Control was defined as $\mathrm{SBP}<140 \mathrm{~mm} \mathrm{Hg}$ and $\mathrm{DBP}<90 \mathrm{~mm} \mathrm{Hg}$ in treated adults with hypertension.

We investigated a range of self-reported participants' characteristics for associations with antihypertensive use and BP control. Socio-demographic characteristics included age, gender and socio-economic status based on income, education and occupation. ${ }^{22} \mathrm{~A}$ medical interview covered health conditions and previous medical diagnoses, such as diabetes mellitus (excluding having diabetes during pregnancy), coronary heart disease (CHD) or stroke. Alcohol consumption was measured using the validated German-language version ${ }^{23}$ of the three questions for the Alcohol Use Disorders Identification Test (AUDIT-C) as a brief screening test for heavy drinking and/or active alcohol abuse or dependence. Women and men with more than 4 and 5 points, respectively, on the 12-point scale were classified as high-risk alcohol drinkers. ${ }^{24}$ Smoking status was categorized as daily or occasional smoker, ex-smoker and never smoked. Physical activity was categorized as no physical activity, up to $2 \mathrm{~h}$ per week, $2-4 \mathrm{~h}$ per week and $>4$ h per week. ${ }^{25}$

\section{Statistical analysis}

Cross-sectional and trend analyses were conducted using a weighting factor which corrects for deviations in the sample from the population structure with regard to age, sex, region of residence, nationality, as well as municipality size and educational level, reflecting the German population as of 31 December 2010. DEGS1-weights of former GNHIES98 participants additionally included adjustment for re-participation probability. ${ }^{19}$

Cross-sectional analysis was used for gender differences between 1998 and 2008-2011. Changes of gender differences over time were tested in a combined data set with 1998 and 2008-2011 data in logistic regression models, including an interaction term of sex with a survey for all dependent variables presented in Table 1.

To examine relations between BP control and socio-demographics, health characteristics and antihypertensive use, adjusted odds ratios and 95\% confidence interval $(95 \%$ CI $)$ were determined using multivariable logistic regression models. Interactions of sex with all other independent variables were tested for control of BP among the younger (18-54 years) and the older (55-79 years) groups.

The SPSS-20 Complex Samples method was used in the analysis to account for the weighting and clustering because of the two-stage sampling procedure. Group differences were considered statistically significant for $P$-values $<0.05$.

\section{RESULTS}

The overall prevalence of hypertension (which includes controlled hypertension) as well as the prevalence of adults (18-79 years) with a $\mathrm{BP} \geqslant 140 / 90 \mathrm{~mm} \mathrm{Hg}$ (which is uncontrolled hypertension) in Germany for 2008-2011 was significantly higher in men than in women (33.4 vs. $30.0 \%$ and 18.1 vs. $12.7 \%$, respectively). These gender differences were driven by the younger group (18-54 years; Table 1). In 1998, the prevalence of hypertension and of BP $\geqslant 140 / 90 \mathrm{~mm} \mathrm{Hg}$ in the overall age-group had not differed by gender, and the gender differences in the younger group were less pronounced than in 2008-2011. The gender gaps in the prevalence of hypertension and in the prevalence of $\mathrm{BP} \geqslant 140 / 90 \mathrm{~mm} \mathrm{Hg}$ have increased in this 10 -year period in Germany ( $P$-value for interaction gender by survey from logistic regression models in the combined data set was 0.010 in the model for hypertension and was 0.000 in the model for $\mathrm{BP} \geqslant 140 / 90 \mathrm{~mm} \mathrm{Hg}$ ).

In 1998, 18-79-year-old men had a mean SBP of $130.7 \mathrm{~mm} \mathrm{Hg}$ (95\% CI 130.0-131.5) and a mean DBP of $78.5 \mathrm{~mm} \mathrm{Hg}(95 \% \mathrm{CI}$ 78.1-79.0), whereas 18-79-year-old women had a mean SBP of 127.3 $\mathrm{mm} \mathrm{Hg}$ (95\% CI 126.4-128.3) and a mean DBP of $78.0 \mathrm{~mm} \mathrm{Hg}$ (95\% CI 77.5-78.6). In 2008-2011, mean SBP in men was $127.4 \mathrm{~mm} \mathrm{Hg}$ (95\% CI 126.7-128.1), whereas in women it was $7.6 \mathrm{~mm} \mathrm{Hg}$ lower (120.8 mm Hg; 95\% CI 120.1-121.5). Mean DBP was $75.3 \mathrm{~mm} \mathrm{Hg}$ in men (95\% CI 74.8-75.8), whereas in women it was $4.1 \mathrm{~mm} \mathrm{Hg}$ lower $(71.2 \mathrm{~mm} \mathrm{Hg}$; 95\% CI 70.8-71.6; Figure 1).

In 2008-2011 as well as in 1998, awareness, treatment and control rates among adults aged 18-79 years with hypertension were higher in women than in men (Table 1). These gender differences were larger in younger adults (18-54 years) compared with older adults (55-79 years), in whom they were statistically significant only for treatment but not for awareness and control. When the treatment was analyzed, in those aware of hypertension (to separate the gender difference in awareness from that in treatment), the gender difference was still apparent in the overall and younger groups in both surveys. Control of hypertension among the treated adults, on the other hand, had been 
Table 1 Gender differences in hypertension in Germany 1998 and 2008-2011 (weighted to the population 2010)

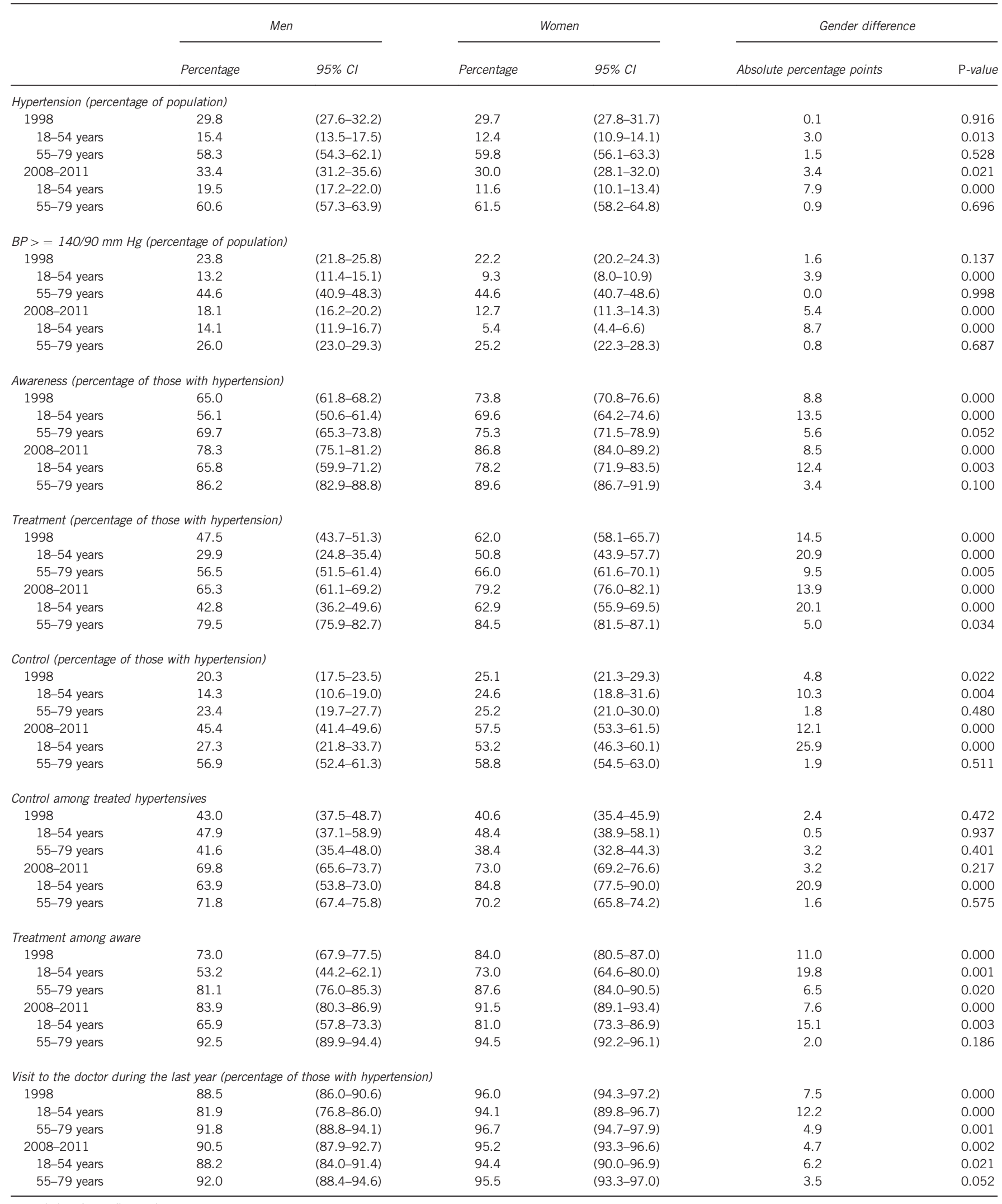

Abbreviation: $\mathrm{Cl}$, confidence interval.

*1998-Ds: 1998 blood pressure values calibrated for comparison with Datascope measurements.

$P$-values are for gender differences. 

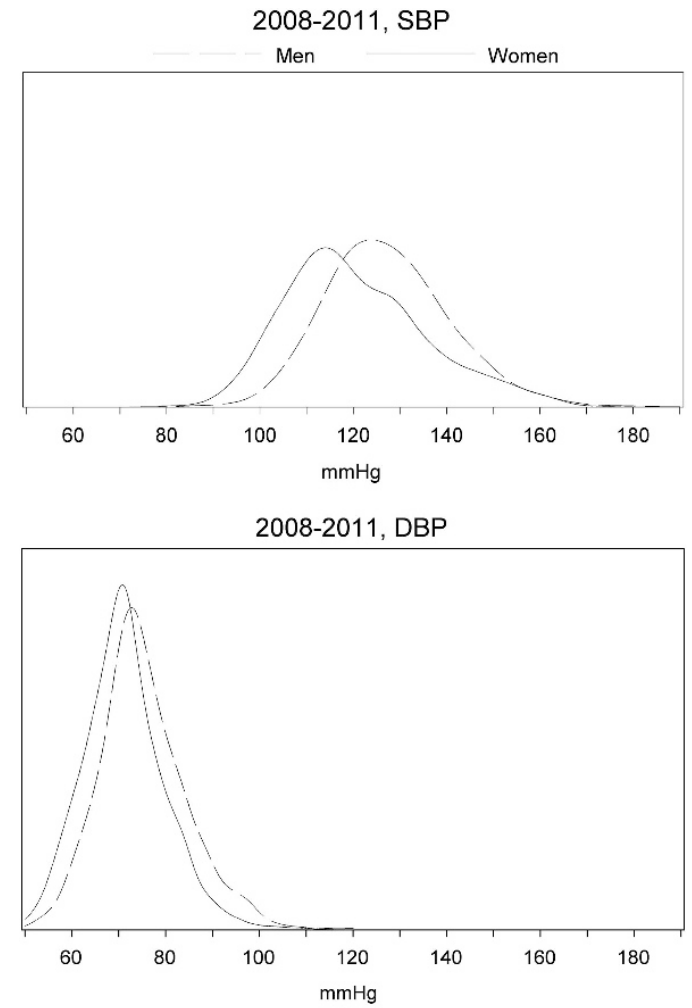

1998-Ds, SBP

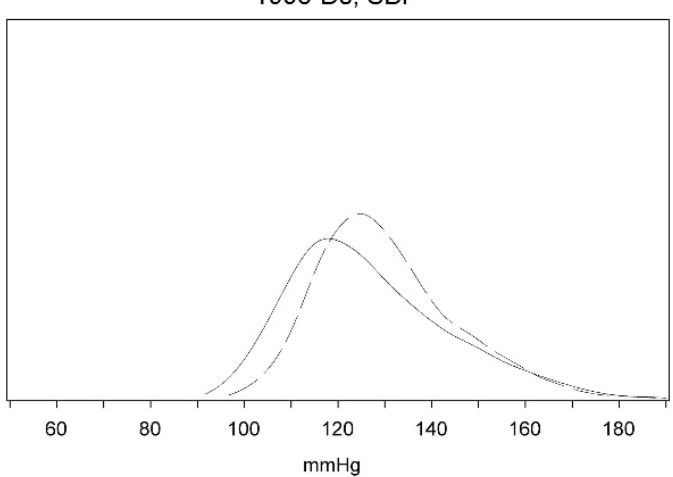

998-Ds, DBP

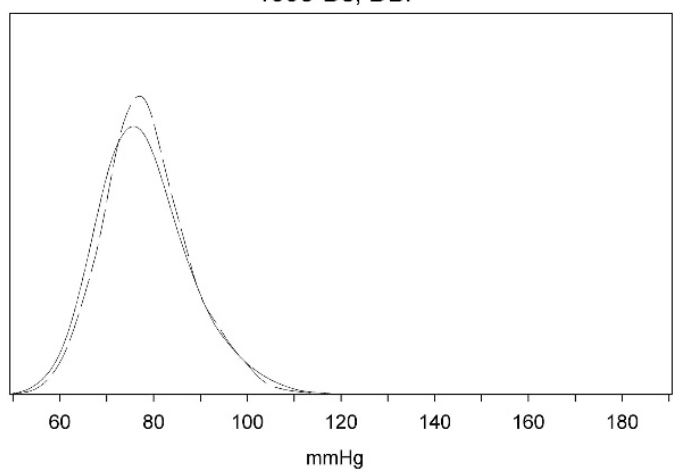

Figure 1 Density curves representing the distribution of SBP and DBP in adults aged 18-79 years in Germany 1998 and 2008-2011, weighted to the population as of 31 December 2010.

similar in women and men in 1998 in both age groups and improved in all age-gender subgroups in 2008-2011. Nevertheless, the magnitude of the improvement (both in relative and absolute percentage points) was only half as large in younger men compared with the other three age-gender groups (older men, younger women and older women). This disparity in magnitude of improvement resulted in a new gender gap in control of hypertension among those treated for hypertension in 18-54-year-olds with $84.8 \%$ control among treated women but only $63.9 \%$ control among treated men (interaction gender by survey $P=0.012$ ).

Data regarding BP measurement patterns were mainly available for 2008-2011. Little information on health-care utilization was available for both time periods, such as the proportion of adults who visited a doctor in the year preceding the survey (for any indication), which was somewhat higher in women compared with men (in 1998: $96.0 \mathrm{vs.}$ $88.5 \%$, respectively, and in 2008-2011: 95.2 vs. 90.5\%, respectively; Table 1). Among adults aware of hypertension in 2008-2011, women had a significantly higher proportion of BP self-measurement than men (79.6 vs. $73.6 \%$, respectively; Table 2). This gender difference was almost entirely driven by the younger group, where more women aware of hypertension measured their BP themselves compared with men aware of hypertension (76.4 vs. 59.2\%, respectively). However, when considering regular (at least once a week) self-measurement, no statistically significant difference between men and women was observed (38.8 vs. $34.5 \%$, respectively). Similarly, BP measurement by a health professional in the last 4 weeks and in the last 12 months did not differ by gender. However, there were more men without any BP monitoring (no health-professional measurement and no selfmeasurement) than women (2.4 vs. $0.8 \%$, respectively). Hospital admissions as well as emergency healthcare owing to hypertension were rather rare; however, there were significantly higher hospital admissions for women than for men, particularly in the older agegroup (Table 2).

Antihypertensive therapy was analyzed in detail. The proportion of monotherapy and polytherapy was similar for men and for women in both surveys. The number of drugs used to treat hypertension in 2008-2011 did not differ by gender. One-third of treated adults with hypertension used only one antihypertensive drug (men 32.7\%, women $33.5 \%$ ), $32.4 \%$ of men and $30.2 \%$ of women used two antihypertensive drugs and $34.9 \%$ of men and $36.3 \%$ of women used three or more antihypertensive drugs.

The proportions of specific antihypertensive drug class use in 2008-2011 were quite similar for men and women in the overall age-group (Figure 2), with the exception of a higher use of ACEI in men compared with women (53 vs. 37\% $P=0.000$ ). However, a gender difference in the use of $\beta$-blockers became apparent only when comparing age-gender groups (Table 3). Among the younger group, men used less $\beta$-blockers than women (42.3 vs. 60.8\%, respectively). These gender differences in the use of $\beta$-blockers and ACEI were not observed in the 1998 data.

Because of the gender gap in the control rate among treated young adults (Table 1), as well as the age-dependent gender differences in 2008-2011 in the specific antihypertensive drug class used (Table 3), we have separately explored in multivariable logistic regression models factors that can influence BP control in the younger and in the older group (Table 4). These analyses included socio-demographic variables (sex, age and socio-economic status); lifestyle factors, such as physical exercise and alcohol drinking; antihypertensive therapy type (mono vs. polytherapy); as well as the different drug classes and cardiovascular risk indicators that may influence both therapy and health behavior, such as previous $\mathrm{CHD}$ or stroke, diabetes, obesity, smoking and BP self-measurement. Different factors appear to influence the control of younger and older treated adults with hypertension. In the younger group, control of hypertension among treated adults was positively 
Table 2 Blood pressure measurement and health-care utilization in adults aware of hypertension in Germany DEGS 2008-2011

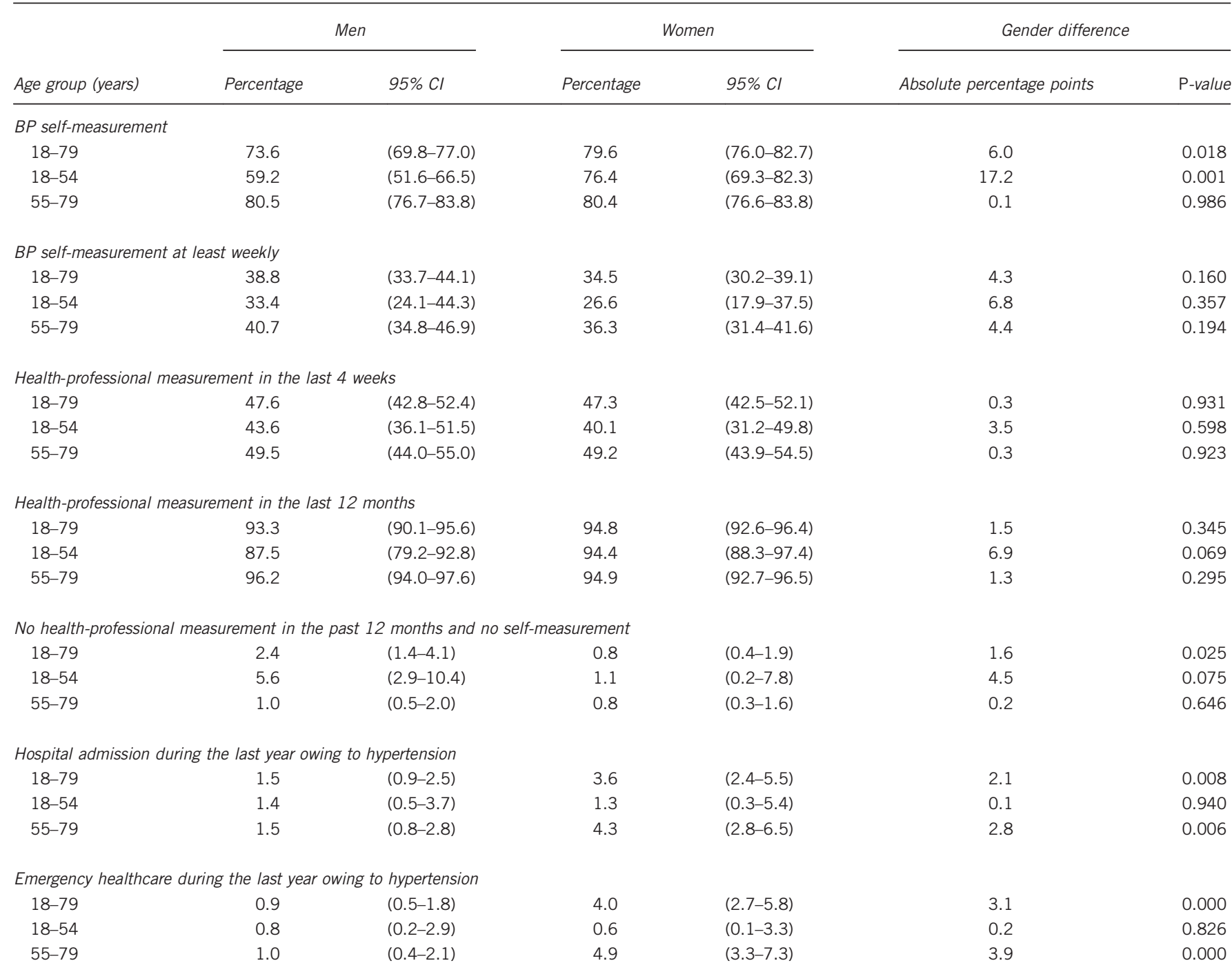

Abbreviations: BP, blood pressure; $\mathrm{Cl}$, confidence interval.

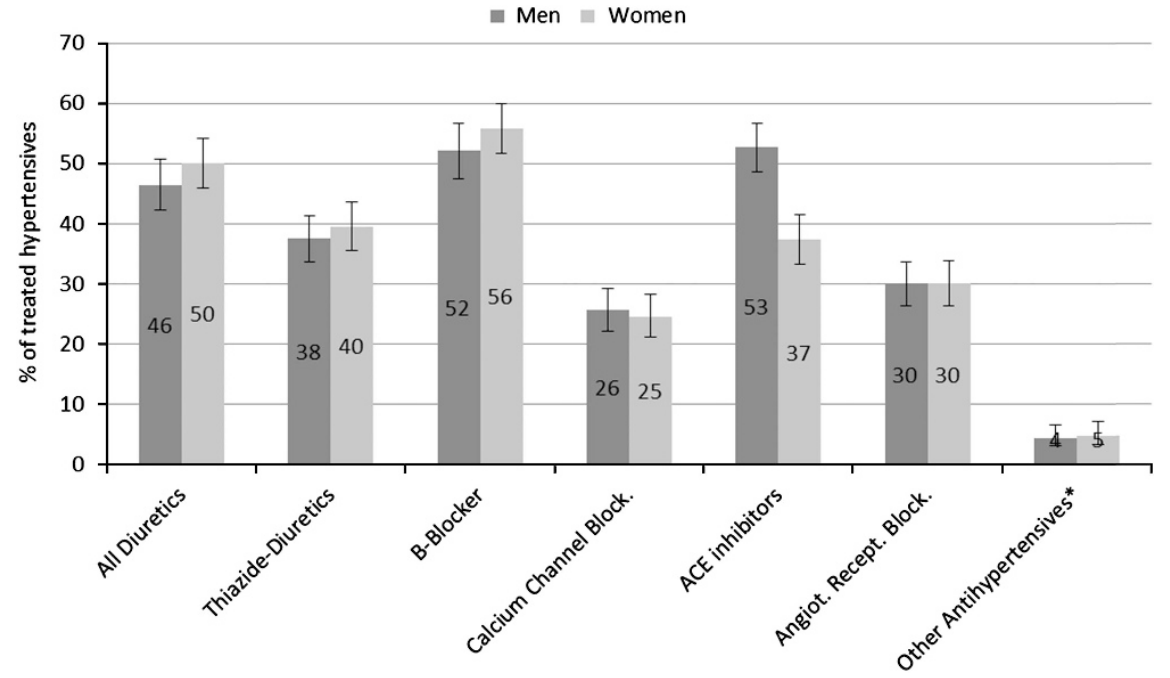

Figure 2 Antihypertensive medication use (mono and polytherapy) among adult men and women with treated hypertension in Germany 2008-2011. *Other antihypertensives from the ATC (Anatomical Therapeutic Chemical) code: CO2. ACE: angiotensin-converting enzyme. 
Table 3 Antihypertensive medication use (mono and polytherapy) among adults with treated hypertension in Germany 2008-2011 stratified by age and sex

\begin{tabular}{|c|c|c|c|c|c|c|c|c|}
\hline \multirow[b]{2}{*}{ Drug class } & \multicolumn{4}{|c|}{ 18-54 years } & \multicolumn{4}{|c|}{ 55-79 years } \\
\hline & Men \% $(95 \% \mathrm{Cl})$ & Women \% $(95 \% \mathrm{Cl})$ & $\begin{array}{l}\text { Gender difference } \\
\text { absolute percen- } \\
\text { tage points }\end{array}$ & P-value & Men \% $(95 \% \mathrm{Cl})$ & Women \% (95\% Cl) & $\begin{array}{l}\text { Gender difference } \\
\text { absolute percen- } \\
\text { tage points }\end{array}$ & P-value \\
\hline Diuretics all & $34.3(26.3-43.2)$ & $36.8(28.5-46.1)$ & 2.5 & 0.677 & $50.1(45.5-54.7)$ & $53.9(49.3-58.4)$ & 3.8 & 0.271 \\
\hline $\mathrm{CCB}$ & $23.6(17.1-31.8)$ & $18.8(12.3-27.7)$ & 7.8 & 0.392 & $26.3(22.7-30.3)$ & $26.3(22.5-30.4)$ & 0 & 0.981 \\
\hline ACEI & $51.4(42.7-60.0)$ & $35.1(27.5-43.6)$ & 16.3 & 0.010 & $52.5(47.7-57.3)$ & $38.2(33.9-42.7)$ & 14.3 & 0.000 \\
\hline ARB & $27.9(21.0-36.0)$ & $25.3(17.9-34.6)$ & 2.6 & 0.672 & $31.2(27.3-35.4)$ & $31.7(27.6-36.1)$ & 0.5 & 0.868 \\
\hline $\begin{array}{l}\text { Antihypertensives } \\
\text { (ATC: C02) }\end{array}$ & $2.6(1.1-6.1)$ & $4.1(1.7-9.7)$ & 1.5 & 0.493 & $5.5(3.6-8.4)$ & $5.0(3.2-7.7)$ & 0.5 & 0.740 \\
\hline
\end{tabular}

Abbreviations: ACEI, angiotensin-converting enzyme inhibitor; ARB, angiotensin-receptor blockers; ATC, anatomical therapeutic chemical; CCB, calcium-channel blockers; Cl, confidence interval.

associated with female gender and with treatment with $\beta$-blockers, ACEI and ARB. Conversely, in the older group of adults, gender was not associated with control of hypertension among treated adults. However, we found that in the older group of adults, diabetes was negatively associated, whereas CHD or stroke was positively associated with control of hypertension among treated adults. Interactions between gender and all other variables were explored in both age groups but were not significant.

\section{DISCUSSION}

Even though great improvements in the management and control of hypertension have been achieved since 1998 among men and women in Germany, men in 2008-2011 were still more likely to be unaware, untreated and uncontrolled regarding hypertension compared with women. These gender differences were much more pronounced in the younger group (hypertensive men vs. women aged 18-54 years: awareness 65.8 vs. $78.2 \%$, respectively; treatment 42.8 vs. $62.9 \%$, respectively; control 27.3 vs. $53.2 \%$, respectively) compared with the older age-group (55-79 years) in whom the gender differences were significant only for treatment but not for awareness or control of hypertension. The gender gap in hypertension management has not changed significantly between 1998 and 2008-2011 with regard to awareness of hypertension, treatment for hypertension, treatment among adults aware of their hypertension and control of hypertension. However, although control of hypertension among treated hypertensives had not differed by gender in 1998, a decade later, the control of hypertension among treated men aged 18-54 years was considerably lower than among treated women (63.9 vs. $84.8 \%$, respectively) because it has not increased at the same pace as in the other agegender groups.

Since 1998, the entire distribution of SBP and DBP in both men and women shifted toward lower values. This shift was more pronounced in women than in men, enlarging the pre-existing gender-gap in mean SBP and leading to a gender gap in mean DBP.

For decades, surveys showed higher awareness, treatment and control rates for hypertension in women compared with men in several European countries, Canada and in the United States. ${ }^{6,10-14}$ A similar trend as in Germany has been reported in Canada and England where hypertension awareness, treatment and control have greatly improved but still remain higher in women. ${ }^{15,26}$

Similar to our study, data from Canada, US and France show that men in general, and particularly younger men, are less likely to be aware of having hypertension. ${ }^{27-29}$ It was suggested that the gender difference in health-care use explains the gender difference in hypertension awareness and that regular medical visits are critical for improving hypertension awareness among young adults and for reducing gender disparities. ${ }^{28}$

Of note, in a more recent US study (2011-2012), similar awareness has been reported for both genders, whereas treatment and control remained higher in women. ${ }^{30}$

Consistent with current international reports, ${ }^{6,29,31}$ we found that hypertensive women are more likely to use antihypertensive medications than men. This was already the case in 1998. However, by analyzing treatment among aware adults in the different gender-age groups, we observed that the gender gap in the older group of adults had disappeared in 2008-2011. One explanation of the still existing gender gap in the overall antihypertensive medication use in Germany could be at least in part because women go more often to the doctor than men, particularly the younger group. Women also have higher hypertension awareness, compared with men; however, even treatment among aware adults was higher in women.

There is strong evidence showing that the efficacy of antihypertensive drugs for reducing BP and, therefore, cardiovascular outcomes does not differ between men and women. ${ }^{32}$ However, few reports suggest that for some treatment regimens this may not be the case. ${ }^{33,34}$ In addition, although the lowering of BP with specific treatment regimens may be similar for men and women, the potential for prevented events may differ between genders if the increase in risk with BP differs, which was recently suggested in an analysis relating systolic nighttime BP to mortality and cardiovascular events. ${ }^{35}$

Age-related factors, concurrent drug treatments, comorbidities and the gender difference in side effects are the key factors that complicate decision making when selecting a therapy. European and American studies have already reported differences in the use of antihypertensive drug classes between men and women. ${ }^{10,36}$ Our study showed significant differences in the use of $\beta$-blockers in the younger group and in the use of ACEI in both age groups. Similarly, in Swedish and US studies, men were more often treated with ACEI than women. ${ }^{37-39}$ This difference could be explained by the threefold increased risk of women to develop ACEI-related dry cough as a side effect. ${ }^{40}$ Furthermore, the gender difference in ACEI use among the young group could also be owing to the potential ACEI teratogenicity leading to less frequent prescriptions in women of child-bearing age. ${ }^{9}$ The 
Table 4 Factors associated with blood pressure control stratified by age group among adults with treated hypertension

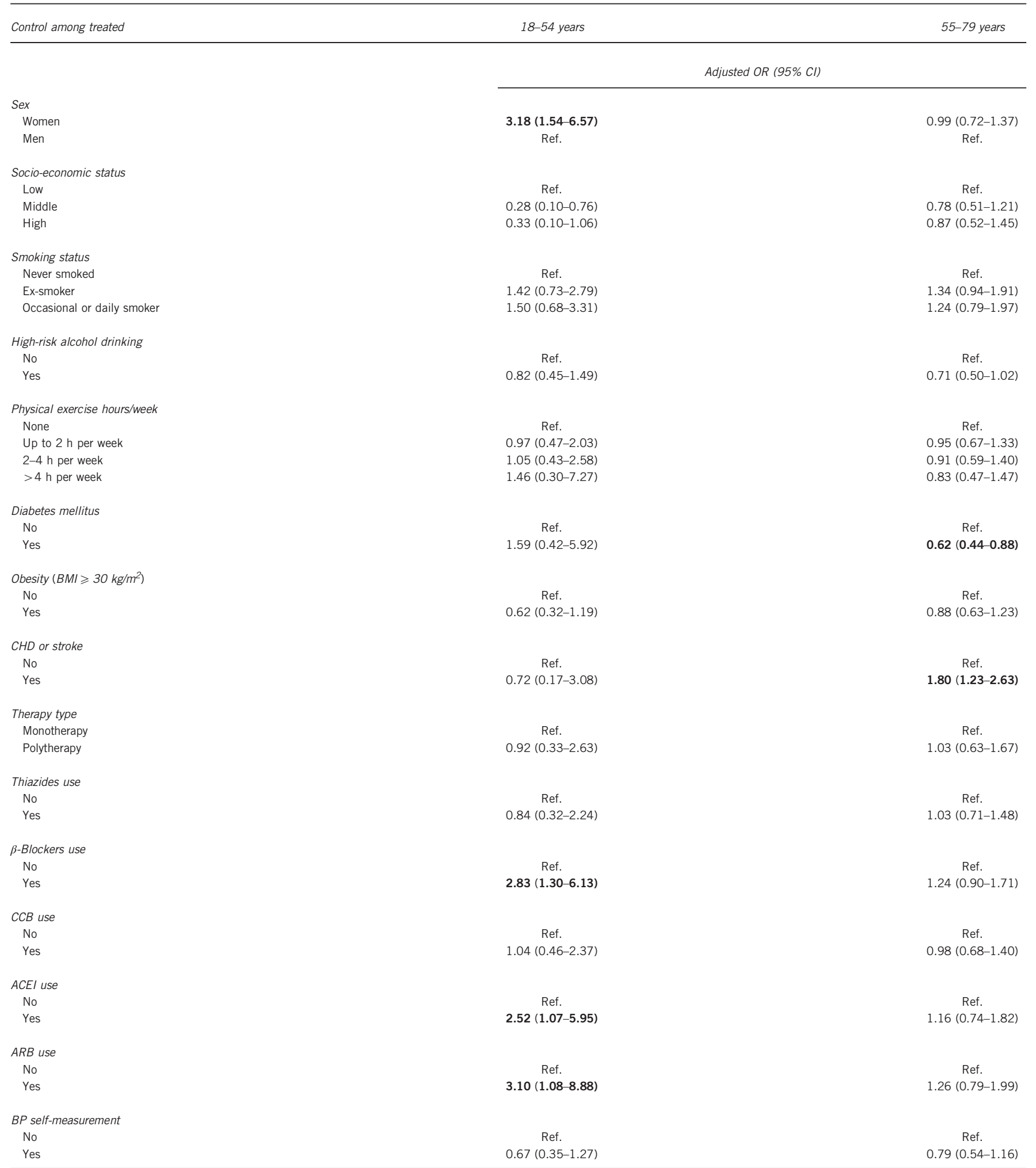

Abbreviations: ACEl: angiotensin-converting enzyme inhibitor; ARB, angiotensin-receptor blockers; BMI, body mass index; BP, blood pressure; CCB, calcium-channel blockers; CHD, coronary heart disease; $\mathrm{Cl}$, confidence interval; OR, odds ratio, Ref., reference.

German Health interview and Examination Survey for adults (DEGS1) 2008-2011.

Bold text denotes statistical significance $(P<0.05)$ in comparison with the reference. 
gender difference in $\beta$-blockers use among the younger group could be related to the erectile dysfunction side effect of $\beta$-blockers. ${ }^{41,42}$

The proportion of monotherapy and polytherapy users in Germany was similar for men and women in both surveys for 1998 and 2008-2011. Conversely, in France in 2006-2007 men were significantly more often treated with polytherapy than women (66.4 vs. $47.0 \%$, respectively, $P=0.004) .{ }^{29}$ In line with other studies, we found no gender difference in using 1, 2, 3 or more antihypertensives between men and women. ${ }^{43,44}$

The gender gap that we have found in hypertension control is related to the gender gap in treatment. However, we also detected a gender gap in control of hypertension among treated adults. Unlike many other studies reporting a gender difference in the control rate of the older treated hypertensives (women more likely to be uncontrolled), ${ }^{10,38,43,45,46}$ in our study we found no difference in the older group of adults; we did find a difference in the younger of adults. In 2008-2011 in Germany, we found that young women treated for hypertension had a significantly better control of hypertension compared with young treated men or older treated men and women. Similar to our study, US data analyzed by Daugherty et al. ${ }^{47}$ have found a gender-age disparity in hypertension control, whereas younger men and older women had lower BP control compared with their peers. More recent US data indicate that although gender differences in antihypertensive treatment continue to exist, BP control rates among treated hypertensives are now essentially the same between men and women. ${ }^{6}$ Reports from France and Switzerland support that control of treated hypertensives is significantly more frequent in women than in men. ${ }^{29,48}$ The Canadian experience showed that educational programs and interventions for the public and health-care professionals help reduce the gender gap in hypertension management. ${ }^{15}$ England has recently launched a new action plan to improve the prevention, detection and management of hypertension across the population. ${ }^{49}$ Furthermore, initiatives, such as the world Hypertension Day, are also useful to raise awareness of hypertension.

Among adults aware of hypertension in Germany 2008-2011, women had a significantly higher proportion of BP selfmeasurement than men; however, the difference is not large (79.6 vs. $73.6 \%$, respectively). In line with a Canadian survey, ${ }^{50}$ no gender difference was found when analyzing the regular (at least weekly) self-measurement. In Germany, more than one-third of adults with hypertension monitored at least weekly their BP, which is more frequent than in Canada (26.2\%). ${ }^{50}$ Nevertheless, these selfmeasurement rates should improve because evidence has shown that self-monitoring helps control BP. ${ }^{7,8}$

Our finding that older adults with hypertension and diabetes were less likely to have $\mathrm{BP}$ control than their respective reference group was also observed internationally. $6,43,51$ A Korean cross-sectional study of adults aged $\geqslant 60$ years showed that diabetes was negatively associated with hypertension control in both genders; however, the negative association was stronger in women (odds ratio $=0.23 ; P<0.001$ ) than in men (odds ratio $=0.30 ; P=0.010$ ). ${ }^{52}$

On the other hand, having had $\mathrm{CHD}$ or stroke was positively associated with BP control. This could be because of an increased awareness and a more careful medical management of patients with known cardiovascular disease. This has great public health implications, as the control of $\mathrm{BP}$ results in a significant cardiovascular mortality reduction. ${ }^{53}$

The strengths of our study include the large countrywide samples of non-institutionalized adults in Germany, the highly standardized BP measurements and the comprehensive medication data based on
ATC-coded medication packages and not on recall information. The re-participation rate was $64 \%$, and we cannot exclude selection bias; however, the whole response (new participants as well as re-participation) was not differential between men and women. In addition, although weighting cannot eliminate completely selection bias, it could ensure that the distribution of key socio-demographic variables in our sample reflects the population living in Germany. ${ }^{54}$

However, one of our limitations is that severely ill and institutionalized persons could not participate in the surveys, as well as those with generally low adherence to treatment might be underrepresented in a health survey, which may possibly lead to an overestimation of treatment and control rates. Furthermore, antihypertensive use and BP control depend on treatment adherence, which cannot be directly analyzed with our data. Another limitation is that BP was measured on 1 single day, which is customary in epidemiological studies, whereas the diagnosis of hypertension and treatment decisions in clinical practice are based on elevated BP values on several occasions. High BP values may be lower on subsequent occasions owing to a regression to the mean phenomenon. However, this does not necessarily mean that we overestimated uncontrolled hypertension because BP in epidemiological studies is resting BP after a defined and standardized resting time, which is likely to be somewhat lower than casual BP taken in clinical practice.

In conclusion, even though great improvement in hypertension management and control was achieved in the last decades, the gender gap concerning higher awareness, treatment and control in women has not yet narrowed. In addition, our study shows that gender disparities in hypertension management may be masked because they are agedependent. A greater understanding of psychosocial factors affecting detection, treatment and care of hypertension complemented by research on the physiology and pathophysiology of BP control in men and women is needed. Targeting high-risk groups could help improving BP control and, therefore, reduce cardiovascular morbidity and mortality.

\section{CONFLICT OF INTEREST}

The authors declare no conflict of interest.

\section{ACKNOWLEDGEMENTS}

This study has been financed by the German Federal Ministry of Health and by the Robert Koch Institute.

1 Perk J, De Backer G, Gohlke H, Graham I, Reiner Z, Verschuren M, Albus C, Benlian P, Boysen G, Cifkova R, Deaton C, Ebrahim S, Fisher M, Germano G, Hobbs R, Hoes A, Karadeniz S, Mezzani A, Prescott E, Ryden L, Scherer M, Syvanne M, Scholte op Reimer WJ, Vrints C, Wood D, Zamorano JL, Zannad F, European Association for Cardiovascular Prevention and Rehabilitation (EACPR)ESC Committee for Practice Guidelines (CPG). European Guidelines on cardiovascular disease prevention in clinical practice (version 2012). The Fifth Joint Task Force of the European Society of Cardiology and Other Societies on Cardiovascular Disease Prevention in Clinical Practice (constituted by representatives of nine societies and by invited experts). Eur Heart $J$ 2012; 33: 1635-1701.

2 Vollmer WM, Sacks FM, Ard J, Appel LJ, Bray GA, Simons-Morton DG, Conlin PR, Svetkey LP, Erlinger TP, Moore TJ, Karanja N, Group DA-STCR. Effects of diet and sodium intake on blood pressure: subgroup analysis of the DASH-sodium trial. Ann Intern Med 2001; 135: 1019-1028.

3 Elmer PJ, Obarzanek E, Vollmer WM, Simons-Morton D, Stevens VJ, Young DR, Lin PH, Champagne C, Harsha DW, Svetkey LP, Ard J, Brantley PJ, Proschan MA, Erlinger TP, Appel LJ, Group PCR. Effects of comprehensive lifestyle modification on diet, weight, physical fitness, and blood pressure control: 18-month results of a randomized trial. Ann Intern Med 2006; 144: 485-495.

4 Law MR, Morris JK, Wald NJ. Use of blood pressure lowering drugs in the prevention of cardiovascular disease: meta-analysis of 147 randomised trials in the context of expectations from prospective epidemiological studies. BMJ 2009; 338: b1665. 
5 Calhoun DA, Jones D, Textor S, Goff DC, Murphy TP, Toto RD, White A, Cushman WC, White W, Sica D, Ferdinand K, Giles TD, Falkner B, Carey RM, American Heart Association Professional Education C. Resistant hypertension: diagnosis, evaluation, and treatment: a scientific statement from the American Heart Association Professional Education Committee of the Council for High Blood Pressure Research. Circulation 2008; 117: e510-e526.

6 Gu Q, Burt VL, Dillon CF, Yoon S. Trends in antihypertensive medication use and blood pressure control among United States adults with hypertension: the National Health And Nutrition Examination Survey, 2001 to 2010. Circulation 2012; 126 2105-2114.

7 Bray EP, Holder R, Mant J, McManus RJ. Does self-monitoring reduce blood pressure? Meta-analysis with meta-regression of randomized controlled trials. Ann Med 2010; 42: 371-386.

8 Uhlig K, Patel K, Ip S, Kitsios GD, Balk EM. Self-measured blood pressure monitoring in the management of hypertension: a systematic review and meta-analysis. Ann Intern Med 2013; 159: 185-194.

9 ESH/ESC. 2013 Practice guidelines for the management of arterial hypertension of the European Society of Hypertension (ESH) and the European Society of Cardiology (ESC) ESH/ESC Task Force for the Management of Arterial Hypertension. J Hypertens 2013; 31: 1925-1938.

$10 \mathrm{Gu}$ Q, Burt VL, Paulose-Ram R, Dillon CF. Gender differences in hypertension treatment, drug utilization patterns, and blood pressure control among US adults with hypertension: data from the National Health and Nutrition Examination Survey 1999-2004. Am J Hypertens 2008; 21: 789-798.

11 Joffres MR, Ghadirian P, Fodor JG, Petrasovits A, Chockalingam A, Hamet P. Awareness, treatment, and control of hypertension in Canada. Am J Hypertens 1997; 10 (10 Pt 1): 1097-1102.

12 Neuhauser HK, Adler C, Rosario AS, Diederichs C, Ellert U. Hypertension prevalence, awareness, treatment and control in Germany 1998 and 2008-11. J Hum Hypertens 2015; 29: 247-253

13 Primatesta P, Poulter NR. Improvement in hypertension management in England: results from the Health Survey for England 2003. J Hypertens 2006; 24: 1187-1192.

14 Wolf-Maier K, Cooper RS, Kramer H, Banegas JR, Giampaoli S, Joffres MR, Poulter N Primatesta $\mathrm{P}$, Stegmayr B, Thamm M. Hypertension treatment and control in five European countries, Canada, and the United States. Hypertension 2004; 43: 10-17.

15 Onysko J, Maxwell C, Eliasziw M, Zhang JX, Johansen H, Campbell NR, Canadian Hypertension Education Program. Large increases in hypertension diagnosis and treatment in Canada after a healthcare professional education program. Hypertension 2006; 48: 853-860.

16 Falaschetti E, Mindell J, Knott C, Poulter N. Hypertension management in England: a serial cross-sectional study from 1994 to 2011. Lancet 2014; 383: 1912-1919.

17 Sarganas G, Knopf H, Grams D, Neuhauser HK. Trends in antihypertensive medication use and blood pressure control among adults with hypertension in Germany. Am J Hypertens 2015; 29: 104-113.

18 Thefeld W, Stolzenberg H, Bellach BM. The Federal Health Survey: response, composition of participants and non-responder analysis. Gesundheitswesen 1999; 61 Spec No, S57-S61.

19 Scheidt-Nave C, Kamtsiuris P, Gosswald A, Holling H, Lange M, Busch MA, Dahm S, Dolle R, Ellert U, Fuchs J, Hapke U, Heidemann C, Knopf H, Laussmann D, Mensink GB, Neuhauser H, Richter A, Sass AC, Rosario AS, Stolzenberg H, Thamm M, Kurth BM. German health interview and examination survey for adults (DEGS)-design, objectives and implementation of the first data collection wave. BMC Public Health 2012; 12: 730.

20 Neuhauser HK, Ellert U, Thamm M, Adler C. Calibration of blood pressure data after replacement of the standard mercury sphygmomanometer by an oscillometric device and concurrent change of cuffs. Blood Press Monit 2014; 20: 39-42.

21 Knopf H, Grams D. Medication use of adults in Germany: results of the German Health Interview and Examination Survey for Adults (DEGS1). Bundesgesundheitsblatt Gesundheitsforschung Gesundheitsschutz 2013; 56: 868-877.

22 Lampert T, Kroll L, Muters S, Stolzenberg H. Measurement of socioeconomic status in the German Health Interview and Examination Survey for Adults (DEGS1). Bundesgesundheitsblatt Gesundheitsforschung Gesundheitsschutz 2013; 56: 631-636.

23 Dybek I, Bisch of G, Grothues J, Reinhardt S, Meyer C, Hapke U, John U, Broocks A, Hohagen F, Rumpf HJ. The reliability and validity of the Alcohol Use Disorders Identification Test (AUDIT) in a German general practice population sample. J Stud Alcohol 2006; 67: 473-481.

24 Bush K, Kivlahan DR, McDonell MB, Finn SD, Bradley KA. The AUDIT alcohol consumption questions (AUDIT-C): an effective brief screening test for problem drinking. Ambulatory Care Quality Improvement Project (ACQUIP). Alcohol Use Disorders Identification Test. Arch Intern Med 1998; 158: 1789-1795.

25 Krug S, Jordan S, Mensink GB, Muters S, Finger J, Lampert T. Physical activity: results of the German Health Interview and Examination Survey for Adults (DEGS1) Bundesgesundheitsblatt Gesundheitsforschung Gesundheitsschutz 2013; 56: 765-771.

26 Falaschetti E, Chaudhury M, Mindell J, Poulter N. Continued improvement in hypertension management in England: results from the Health Survey for England 2006. Hypertension 2009; 53: 480-486.

27 Gee ME, Bienek A, McAlister FA, Robitaille C, Joffres M, Tremblay MS, Johansen H, Campbell NR. Factors associated with lack of awareness and uncontrolled high blood pressure among Canadian adults with hypertension. Can J Cardiol 2012; 28: 375-382.

28 Everett B, Zajacova A. Gender differences in hypertension and hypertension awareness among young adults. Biodemography Soc Biol 2015; 61: 1-17.
29 Godet-Mardirossian H, Girerd X, Vernay M, Chamontin B, Castetbon K, de Peretti C. Patterns of hypertension management in France (ENNS 2006-2007). Eur J Prev Cardiol 2012: 19: 213-220.

30 Nwankwo T, Yoon SS, Burt V, Gu Q. Hypertension among adults in the United States: National Health and Nutrition Examination Survey, 2011-2012. NCHS Data Brief 2013; 133: 1-8.

31 Gee ME, Campbell NR, Gwadry-Sridhar F, Nolan RP, Kaczorowski J, Bienek A, Robitaille C, Joffres M, Dai S, Walker RL, Outcomes Research Task Force of the Canadian Hypertension Education Program. Antihypertensive medication use, adherence, stops, and starts in Canadians with hypertension. Can J Cardiol 2012; 28: 383-389.

32 Turnbull F, Woodward M, Neal B, Barzi F, Ninomiya T, Chalmers J, Perkovic V, Li N, MacMahon S, Blood Pressure Lowering Treatment Trialists Collaboration. Do men and women respond differently to blood pressure-lowering treatment? Results of prospectively designed overviews of randomized trials. Eur Heart J 2008; 29: 2669-2680.

33 Matsui K, Kim-Mitsuyama S, Ogawa H, Jinnouchi T, Jinnouchi H, Arakawa K, OlmeSartan Calcium Antagonists Randomized Study Group. Sex differences in response to angiotensin II receptor blocker-based therapy in elderly, high-risk, hypertensive Japanese patients: a subanalysis of the OSCAR study. Hypertens Res 2014; 37 526-532.

34 Safar ME, Myers MG, Leenen F, Asmar R. Gender influence on the dose-ranging of a low-dose perindopril-indapamide combination in hypertension: effect on systolic and pulse pressure. J Hypertens 2002; 20: 1653-1661.

35 Boggia J, Thijs L, Hansen TW, Li Y, Kikuya M, Bjorklund-Bodegard K, Richart T, Ohkubo T, Jeppesen J, Torp-Pedersen C, Dolan E, Kuznetsova T, Olszanecka A, Tikhonoff V, Malyutina S, Casiglia E, Nikitin Y, Lind L, Maestre G, Sandoya E, KaweckaJaszcz K, Imai Y, Wang J, Ibsen H, O'Brien E, Staessen JA, International Database on Ambulatory blood pressure in relation to Cardiovascular Outcomes Investigations. Ambulatory blood pressure monitoring in 9357 subjects from 11 populations highlights missed opportunities for cardiovascular prevention in women. Hypertension 2011; 57: 397-405.

36 Klungel $\mathrm{OH}$, de Boer A, Paes AH, Seidell JC, Bakker A. Sex differences in antihypertensive drug use: determinants of the choice of medication for hypertension. J Hypertens 1998; 16: 1545-1553.

37 Ljungman C, Kahan T, Schioler L, Hjerpe P, Hasselstrom J, Wettermark B, Bostrom KB, Manhem K. Gender differences in antihypertensive drug treatment: results from the Swedish Primary Care Cardiovascular Database (SPCCD). J Am Soc Hypertens 2014; 8 $882-890$.

38 Keyhani S, Scobie JV, Hebert PL, McLaughlin MA. Gender disparities in blood pressure control and cardiovascular care in a national sample of ambulatory care visits. Hypertension 2008; 51: 1149-1155.

39 Carlsson AC, Wandell P, Sundquist K, Johansson SE, Sundquist J. Effects of prescribed antihypertensives and other cardiovascular drugs on mortality in patients with atrial fibrillation and hypertension: a cohort study from Sweden. Hypertens Res 2014; 37: 553-559.

40 Visser LE, Stricker BH, van der Velden J, Paes AH, Bakker A. Angiotensin converting enzyme inhibitor associated cough: a population-based case-control study. J Clin Epidemiol 1995; 48: 851-857.

41 al Khaja KA, Sequeira RP, al Damanhori AH, Mathur VS. Antihypertensive drug associated sexual dysfunction: a prescription analysis-based study. Pharmacoepidemiol Drug Saf 2003; 12: 203-212.

42 La Torre A, Giupponi G, Duffy D, Conca A, Catanzariti D. Sexual dysfunction related to drugs: a critical review. Part IV: cardiovascular drugs. Pharmacopsychiatry 2015; 48: $1-6$.

43 Thoenes M, Neuberger HR, Volpe M, Khan BV, Kirch W, Bohm M. Antihypertensive drug therapy and blood pressure control in men and women: an international perspective. J Hum Hypertens 2010; 24: 336-344.

44 Barrios V, Escobar C, Calderon A, Llisterri JL, Echarri R, Alegria E, Muniz J, Matali A Blood pressure and lipid goal attainment in the hypertensive population in the primary care setting in Spain. J Clin Hypertens 2007; 9: 324-329.

45 Lloyd-Jones DM, Evans JC, Levy D. Hypertension in adults across the age spectrum: current outcomes and control in the community. JAMA 2005; 294: 466-472.

46 Wilkins K, Gee M, Campbell N. The difference in hypertension control between older men and women. Health Rep 2012; 23: 33-40.

47 Daugherty SL, Masoudi FA, Ellis JL, Ho PM, Schmittdiel JA, Tavel HM, Selby JV, O'Connor PJ, Margolis KL, Magid DJ. Age-dependent gender differences in hypertension management. J Hypertens 2011; 29: 1005-1011.

48 Christe V, Waeber G, Vollenweider P, Marques-Vidal P. Antihypertensive drug treatment changes in the general population: the CoLaus study. BMC Pharmacol Toxicol 2014; 15: 20 .

49 Lumley B, Waterall J, Kearney M, Fenton KA. Tackling high blood pressure in England: a new approach. J Clin Hypertens 2015; 17: 575-577.

50 Bancej CM, Campbell N, McKay DW, Nichol M, Walker RL, Kaczorowski J. Home blood pressure monitoring among Canadian adults with hypertension: results from the 2009 Survey on Living with Chronic Diseases in Canada. Can J Cardiol 2010; 26: e152-e157.

51 Wagner A, Sadoun A, Dallongeville J, Ferrieres J, Amouyel P, Ruidavets JB, Arveiler D. High blood pressure prevalence and control in a middle-aged French population and their associated factors: the MONA LISA study. J Hypertens 2011; 29 43-50.

52 Chu SH, Baek JW, Kim ES, Stefani KM, Lee WJ, Park YR, Youm Y, Kim HC. Gender differences in hypertension control among older korean adults: 
Korean social life, health, and aging project. J Prev Med Public Health 2015; 48: 38-47.

53 Chobanian AV, Bakris GL, Black HR, Cushman WC, Green LA, Izzo JL Jr., Jones DW, Materson BJ, Oparil S, Wright JT Jr., Roccella EJ, Joint National Committee on Prevention, Detection, Evaluation, and Treatment of High Blood Pressure. National Heart, Lung, and Blood Institute, National High Blood Pressure Education Program Coordinating Committee. Seventh report of the Joint National Committee on Prevention,
Detection, Evaluation, and Treatment of High Blood Pressure. Hypertension 2003; 42 : 1206-1252.

54 Kamtsiuris $\mathrm{P}$, Lange $M$, Hoffmann $R$, Schaffrath Rosario A, Dahm S, Kuhnert R, Kurth BM. The first wave of the German Health Interview and Examination Survey for Adults (DEGS1): sample design, response, weighting and representativeness. Bundesgesundheitsblatt Gesundheitsforschung Gesundheitsschutz 2013; 56: 620-630.

Supplementary Information accompanies the paper on Hypertension Research website (http://www.nature.com/hr) 